\title{
Almanac 2011: Heart Failure. The National Society Journals Present Selected Research that has Driven Recent Advances in Clinical Cardiology
}

\author{
Andrew L. Clark \\ Heart Failure Association of the European Society of Cardiology, London, United Kingdom
}

\section{EDITORIAL}

\section{NICE, AUDIT AND HEART FAILURE CARE}

The national heart failure audit ${ }^{1}$ in England and Wales continues to grow and provides vital data for planning heart failure services. The first formal report relates to over 6000 patients who were the first 10 patients admitted with a primary diagnosis of heart failure each month to one of 86 hospitals contributing data in 2008-09. Most had left ventricular systolic dysfunction, but an echocardiogram result was available in only $75 \%$. In-patient mortality was $12 \%$ and in survivors, $80 \%$ were receiving an ACE inhibitor (or angiotensin receptor blocker (ARB)), 50\% a $\beta$ blocker and $30 \%$ an aldosterone antagonist at discharge.

The audit for 21000 patients hospitalised with heart failure in 2009-10 is also available. ${ }^{2}$ In-hospital mortality had fallen slightly to $10.5 \%$, but there was no dramatic change in drug prescription rates. Some subsets of patients were particularly likely to be actively treated (men aged 55-64, $\beta$ blocker prescription rate $>70 \%$ ), and others much less likely (women aged $>85, \beta$ blocker prescription rate $40 \%$ ). Aldosterone antagonists were still prescribed for less than half the population.

Two striking features stand out from the data from both audits. First, prescription rates vary greatly, with age-older patients and women being less likely to be treated-and with admission ward-patients admitted to cardiology wards being much more likely to receive active treatment. Second, pharmacological treatment was better for patients admitted under cardiologists, and so was survival. Although a minority of patients admitted with heart failure are managed by cardiologists, the survival benefit persists after correction for age and sex (and other confounders).

The undertreatment of elderly patients with heart failure is a particular cause for concern at a time when patients aged $>80$ represent an increasing proportion of admissions for heart failure. ${ }^{3}$ Treatment of older patients is hampered by their associated comorbidities and polypharmacy and also *as previously published in Heart journal by their systematic exclusion from clinical trials, depriving doctors of the evidence base they need to guide management decisions. ${ }^{4}$ Exclusion of the elderly by trial organisers shows no signs of going away: among 251 trials recruiting patients in December 2008, more than 25\% had an upper age limit for enrolment and more than $80 \%$ excluded patients with comorbid conditions. ${ }^{4}$

The National Institute for Health and Clinical Excellence (NICE) has produced updated guidelines for heart failure care. $\frac{56}{}$ While there has been a lot of comment on the importance of measuring natriuretic peptides as an entry point to heart failure care, NICE has also firmly recommended that care led by a specialist in heart failure should be the norm. This is true at assessment and diagnosis (a patient suspected of having heart failure associated with a previous myocardial infarct or with a very high natriuretic peptide level should receive "...specialist assessment within 2 weeks") and during admission to hospital ("when a patient is admitted to hospital because of heart failure, seek advice on their management plan from a specialist in heart failure").

Such recommendations will impose new burdens. What is a 'specialist'? NICE thinks it is “... a doctor with subspecialty interest in heart failure (often a consultant cardiologist) who leads a specialist multidisciplinary heart failure team of professionals ...", but there are few such individuals available to take up the responsibility. However a specialist is defined, there is no doubt that patients with heart failure fare better when cared for by professionals with a particular interest in their condition. This is reflected in recent US data that have shown lower mortality and readmissions for patients with heart failure managed in high-volume compared with low-volume centres. ${ }^{?}$

One of the problems for a specialist heart failure service is access to advanced treatments such as heart transplantation. Transplantation in the UK is falling, partly owing to a fall in the availability of donor organs, ${ }^{8}$ but just as important is access to expert heart failure care. ${ }^{9}$ We have managed to reconfigure health services to provide primary 
angioplasty for patients with acute myocardial infarction (MI) (including for patients with non-ST elevation MI on rather flimsy evidence $\left.{ }^{10}\right)$. We should do so for patients with heart failure, for whom reconfigured services will have a more far-reaching benefit.

\section{TELEMONITORING}

An exciting possible advance in patient care is the use of remote monitoring to guide changes in treatment. Typically, automated devices in the home can measure weight, pulse rate and heart rhythm and blood pressure and transmit the data to a centre. Abnormal results then trigger patient contact with possible change in treatment. Initial trials have suggested that there may be a benefit from such systems, particularly when coupled with telephone contact.

A particular problem with telemonitoring is what to do with the data. With a large number of patients potentially transmitting quantities of data daily, the resource required to deal with the data might become impossibly large. Attempts to use automated systems have proved disappointing: in a study of 1653 patients who had recently been hospitalised for heart failure, which used telemonitoring with an interactive voice-response system collecting daily information about symptoms and weight, Chaudhry et al found no impact on re-admissions and mortality at 6 months. $\frac{12}{\text { In }}$ another recent study, $\frac{13}{\text { remote monitoring }}$ did not improve outcomes among 710 patients randomised to remote monitoring using a system that transmitted ECG, blood pressure and weight and included a home emergency call system.

It is important to remember that telemonitoring itself does not save lives or admissions, but that actions taken in response to monitoring might do so. The reason recent trials have been neutral may be that 'usual care' in these studies has progressed to the point at which home monitoring can have little additional beneficial effect and it may be that remote monitoring is only likely to be helpful in people at particularly high risk. It may be, too, that the variables measured are simply too crude to be helpful guides to changing treatment.

Another approach to remote monitoring is to use implantable devices to measure haemodynamic changes invasively. The Chronicle device allows pulmonary artery pressure to be measured continuously and an early trial (COMPASS) suggested that it might be helpful. $\stackrel{14}{ }$ A more promising technique, perhaps, is the use of smaller devices implanted directly into the pulmonary artery and communicating using acoustic wireless communication. $\frac{15}{\text { In }}$ the CHAMPION trial, $\frac{16}{} 550$ patients were randomised to have a CardioMEMS device or usual care. The device was used to measure pulmonary artery pressure once a day: it has no internal power source, but uses externally applied radiofrequency energy. Its use was associated with a $30 \%$ reduction in the primary efficacy end point of hospitalisation for heart failure at 6 months. It is not, of course, the devices that improve outcome, but the changes in treatment that follow from device readings. In COMPASS ${ }^{14}$ and CHAMPION,,$\underline{16}$ for example, patients with the device were receiving higher doses of medication to treat heart failure.

The final stage in the evolution of remote monitoring is likely to be to further empowerment of the patient. The devices can be used to transmit data to the person most concerned with the disease-the patient-who can then use the information to make daily changes to his or her treatment. In HOMEOSTASIS, 40 patients with severe heart failure were implanted with a device measuring left atrial pressure and made changes to treatment based on the readings using a preprogrammed hand-held patient advisor module. ${ }^{17}$ It is impossible to draw firm conclusions from such a small observational study, but while diuretic treatment fell as a result of the intervention, $\beta$ blocker and ACE inhibitor/ARB treatment increased. At the same time, mean left atrial pressure fell and there did seem to be a reduction in clinical events.

Invasive monitoring leads to an increase in prescription of medical treatment for heart failure, which highlights another nagging question: although we have clinical trial results to guide us towards 'target' doses of, for example, $\beta$ blockers and ACE inhibitors, how are we to know how much is enough? One possible guide is the use of natriuretic peptides: perhaps treatment should continue to be increased until the natriuretic peptide level is normal. Some small studies point in that direction, others do not: but there is evidence of publication bias in a meta-analysis. ${ }^{18}$ A recent single-centre trial in 364 patients with heart failure showed that treatment guided by $\mathrm{N}$-terminal pro-brain natriuretic peptide was associated with a 1-year mortality identical to treatment guided by a clinical score..$^{19}$ The finding lends some weight to the argument against biomarker-guided treatment but the question will only be resolved by a definitive large trial.

\section{EPIDEMIOLOGY}

\subsection{Heart failure with a normal ejection fraction}

Heart failure with a normal ejection fraction (HeFNEF) remains enigmatic. Epidemiology suggests that it is common, $\frac{21}{21}$ perhaps accounting for half of the cases of heart failure. However, researchers recruiting patients to trials have often found it extremely difficult to identify suitable patients. No clinical trial has as yet identified any successful treatment for HeFNEF and some are sceptical of its existence as a single, well-defined entity..$^{223}$ Problems arise because, at least in part, breathlessness is very common in older people and because some of the diastolic echocardiographic changes thought to indicate that the heart is failing are simply consistent with ageing.

One possibility that has been under-researched is that HeFNEF is more obviously a condition appreciated during exercise, and echocardiographic measurements during exercise may highlight diastolic abnormalities. ${ }^{24}$ An important observation from a study of echocardiography and exercise of over 400 patients with possible HeFNEF 25 was that very few-possibly as few as 3\%-actually had heart failure. Holland and colleagues $\frac{25}{}$ emphasised the importance of measuring the ratio between $\mathrm{E}$ and $\mathrm{E} \mathrm{Q}$ as an index of left ventricular filling pressure, but others have concentrated on much more subtle abnormalities of both systole and diastole in patients with HeFNEF that worsen with exertion. ${ }^{26}$ Impaired left atrial function during exercise may also contribute. $\frac{27}{}$ 
While it remains a very active area of research, the cardinal problem with HeFNEF and the main reason it has no (proven) treatment is the absence of a satisfactory case definition. The incorporation of natriuretic peptides into the diagnostic pathway for HeFNEF should help as a raised level makes it more certain that the heart is the cause of any symptoms. However, natriuretic peptides may show that there has been considerable overdiagnosis of HeFNEF in the past. Potentially relevant in this respect is the recent analysis of mode of death data from I-Preserve: in patients with HeFNEF, death from heart failure was surprisingly rare, the majority succumbing to other cardiovascular events. $\underline{.28}$

\section{TREATMENT}

\subsection{Neurohormonal manipulation}

ACE inhibitors, ARBs and $\beta$ blockers, are of course, the mainstays of medical treatment for patients with chronic heart failure. ACE inhibitors or ARBs should be given to all patients with left ventricular systolic dysfunction, regardless of symptom class, and there is general appreciation that the highest tolerated dose should be used, side effects permitting. Evidence for this approach comes from trials such as ATLAS, ${ }^{29}$ in which patients randomised to higher-dose lisinopril fared better than those receiving a lower dose.

There has been little evidence that a high dose of ARBs is better until the HEAAL study, ${ }^{30}$ in which 3846 patients with heart failure and left ventricular ejection fraction $<40 \%$ and who were intolerant of ACE inhibitors were randomised to receive high-dose (150 $\mathrm{mg}$ ) or low-dose $(50 \mathrm{mg})$ daily losartan. After a median 4.7 years' follow-up there was a lower rate of deaths or hospitalisation for heart failure in the high-dose group ( $\mathrm{HR}=0.90,95 \%$ CI 0.82 to $0.99 ; \mathrm{p}=0.027)$. Thus it does thus seem that up-titrating ARB doses confers clinical benefit.

With RALES ${ }^{31}$ (spironolactone) and EPHESUS ${ }^{32}$ (eplerenone), aldosterone blockade has also become important, with the proviso that aldosterone blockade has not been shown to be beneficial in patients with mild heart failure, at least until recently. In EMPHASIS-HF, ${ }^{33} 2737$ patients with heart failure due to systolic dysfunction and New York Heart Association (NYHA) class II symptoms were randomised to eplerenone (up to $50 \mathrm{mg}$ daily) or placebo, in addition to standard treatment. There was a $37 \%$ reduction in the risk of the primary end point (cardiovascular death or hospitalisation for heart failure) in the eplerenone group, at the cost of a small increase in the risk of hyperkalaemia. It seems likely that guideline groups will now recommend the use of eplerenone in all those with heart failure due to left ventricular systolic dysfunction.

A problem with the more widespread use of aldosterone antagonists is that the risk of life-threatening hyperkalaemia may increase. Certainly after the RALES report, there was a rapid uptake of spironolactone usage resulting in a marked increase in morbidity and mortality from hyperkalaemia. ${ }^{34}$ A possible approach to preventing hyperkalaemia is to use potassium-binding resins. In PEARL-HF, ${ }^{35} 105$ patients with heart failure and a history of hyperkalaemia which had interfered with medical treatment, or who had chronic kidney disease, were recruited. The potassium binder, RLY5016, was given in addition to spironolactone and led to a marked reduction in the risk of hyperkalaemia compared with placebo ( $7.3 \%$ vs $24.5 \%, \mathrm{p}=0.015)$; and a higher proportion of patients reaching spironolactone $50 \mathrm{mg} /$ day (91\% vs $74 \%, \mathrm{p}=0.019)$. These are encouraging data, but lead to the obvious unanswered question: to what extent is the benefit of aldosterone antagonism mediated by hyperkalaemia? If the answer is 'most', or 'all', then potassium binding may not have much to offer.

\subsection{Ivabradine}

The mechanism by which $\beta$ blockers mediate their beneficial effects is not clear, but has long been thought to be related to their ability to reduce heart rate. ${ }^{3637}$ Ivabradine reduces heart rate by reducing sinus node discharge rate while having no other haemodynamic effect and might thus both test the heart rate hypothesis and provide an alternative for patients intolerant of $\beta$ blockers.

In SHIFT, ${ }^{38} 6558$ patients with heart failure and a low ejection fraction and who were in sinus rhythm with a heart rate of at least 70 beats/min were randomised to receive ivabradine or placebo in addition to usual treatment (including $\beta$ blocker, where tolerated). Ivabradine was associated with an $18 \%$ reduction in the primary end point (cardiovascular death or hospital admission for worsening heart failure), driven mainly by a reduction in hospital admission.

The findings of SHIFT have been much discussed. It is important to point out that the benefits of ivabradine were much more striking in those with a higher resting heart rate, ${ }^{38}{ }^{39}$ and that although around $90 \%$ of patients were taking a $\beta$ blocker at baseline, only $23 \%$ were taking a target dose, only $49 \%$ were receiving $\geq 50 \%$ of a target dose and $16 \%$ were receiving a $\beta$ blocker not shown to be beneficial.

The SHIFT findings do suggest that there is a role for ivabradine in patients with chronic heart failure, but it is not a substitute for $\beta$ blocker use. There is an enormous body of evidence supporting the use of $\beta$ blockers, which improve mortality as well as hospitalisation. Ivabradine should be considered only in those patients who still have a resting heart rate above 70 despite maximally tolerated doses of $\beta$ blockers (or perhaps used in patients truly intolerant of $\beta$ blockers). Data from 'real-world' populations of patients with heart failure suggest that the proportion of patients who might be eligible is low, perhaps around $5 \% .{ }^{40}$

\subsection{Iron}

Is iron deficiency a target for treatment? Anaemia is very common in patients with heart failure, ${ }^{41}$ but iron deficiency without anaemia is also common. The best way to manage iron deficiency is not clear: oral iron treatment is widely believed to be ineffective, yet intravenous iron treatment is also thought to be difficult or dangerous. However, a new generation of intravenous iron preparations is now available which allows both rapid and safe administration of iron to patients.

Some preliminary studies suggested that intravenous iron repletion might lead to an improvement in exercise capacity, ${ }^{42}$ and the FAIR-HF study was designed to see if iron might be beneficial in a larger group of patients. ${ }^{43}$ Four hundred and fifty-nine patients were randomised 2:1 to receive iron or placebo infusions (with only the patient blind to treatment). After 6 months, there was an improve- 
ment in patient self-reported global assessment (50\% 'much or moderately improved', compared with $28 \%$ of patients in the placebo group) as well as in secondary end points, including distance covered in a 6 min walk test (about $40 \mathrm{~m}$ increase compared with no change in the placebo group). There were similar improvements regardless of starting haemoglobin.

The results have to be treated with some caution: FAIRHF was not a large trial, blinding was difficult and the end points were to a varying degree subjective. Nevertheless, iron treatment appeared safe and is now an option for patients who remain symptomatic despite medical treatment. An absolutely essential question to answer, though, is the extent to which patients with heart failure should be further investigated for an underlying cause for any iron deficiency, a question not dealt with by FAIR-HF.

Another possible approach for correcting anaemia in heart failure is the use of erythropoiesis-stimulating proteins. A meta-analysis of six randomised controlled trials found that treatment was associated with a significantly lower risk of hospitalisation compared with placebo. ${ }^{44}$ Mortality was unaffected. These outcomes are in contrast with studies in cancer and kidney disease and prompted the authors to a call for a large phase III morbidity and mortality trial of anaemia correction with erythropoiesisstimulating proteins in patients with chronic heart failure.

\subsection{Metabolic manipulation}

The energy-generating processes of the failing cardiac myocyte are abnormal. Some investigators have focused on substrate use: fatty acid metabolism produces a lower yield of ATP for each molecule of oxygen consumed than glucose metabolism (although fatty acid oxidation yields more ATP per mole) and so it makes sense to try to switch metabolism from fatty acids to glucose. ${ }^{45}$

Various approaches have been tried: perhexiline, for example, blocks mitochondrial free fatty acid uptake by inhibiting carnitine palmitoyltransferase. In a small study, perhexiline led to improvements in exercise capacity and left ventricular function and more rapid recovery of phosphocreatine after exercise. ${ }^{46}$ Trimetazidine inhibits lipid $\beta$-oxidation and its use has been associated with both an increase in left ventricular ejection fraction and reduction in resting energy expenditure (known to be high in heart failure). ${ }^{47} \mathrm{~A}$ meta-analysis of the available data for trimetazidine ${ }^{48}$ even suggests that its use might improve mortality and it is surely time for a large-scale trial of metabolic modulators.

\subsection{Cardiac resynchronisation therapy}

Cardiac resynchronisation therapy (CRT: or biventricular pacing) is one of the most exciting new developments for patients with chronic heart failure and left bundle branch block (LBBB) introduced in recent years. Particularly important is its effect on reducing mortality, ${ }^{49}$ but around two-thirds of patients get marked symptomatic benefit from their devices. ${ }^{50}$ That one-third do not has led to the concept of the 'non-responder' to CRT. How to define 'non-response' varies from paper to paper, with some using symptomatic criteria and others using measures of left ventricular function. What has proved difficult to answer is whether 'nonresponse' is related to lack of mortality benefit.
A great deal of time and effort has been expended on trying to identify which patients might benefit from CRT. The severity of symptoms does not seem to matter greatly: those with modest symptoms appear to gain as much mortality benefit as those with worse NYHA class of symptoms. ${ }^{51}$ In MADIT-CRT, ${ }^{52} 1820$ patients with NYHA class I or II symptoms and LBBB were randomised 2:1 to receive CRT (or not) in addition to a defibrillator. There was a $34 \%$ reduction in the risk of death or a heart failure event (defined as congestion treated either with intravenous treatment (diuretics, nesiritide or inotrope) for more than $2 \mathrm{~h}$, regardless of the setting, or: with an increased heart failure regimen during formal hospital admission). The reduction in risk was driven by a reduction in heart failure events. In RAFT, ${ }^{53}$ which included 1438 patients with mild (NYHA class II) symptoms, CRT added to a defibrillator led to a reduction in the rate of death and hospitalisation for heart failure.

Another possible selection criterion is the presence of dyssynchrony on some form of cardiac imaging. Underlying this approach is the assumption that CRT works by improving ventricular coordination, which in turn must in some way be measurable. However, of the large, randomised trials showing a mortality benefit for CRT, none used measures of dyssynchrony as an entry criterion other than a minority of patients in CARE-HF. Vigorous efforts to prove the robustness of any of the very many potential measures of dyssynchrony have failed thus far, with the PROSPECT study of nearly 500 patients being the largest available set of data. ${ }^{54}$ There was poor reproducibility of the measures, none of which related strongly to the assessment of response.

The only selection criteria consistently shown to be related to outcome are electrocardiographic. It is a commonplace observation that the mean QRS duration in the mortality trials of CRT was around 150 ms and where it has been analysed, the broader the QRS, the greater the benefit. Subgroup analysis of PROSPECT showed some symptomatic benefit for CRT in patients with mechanical dyssynchrony and a narrow QRS complex ${ }^{55}$ and similar findings have been reported in small single-centre trials. ${ }^{56}$ There is no doubt, however, that the benefits of CRT are largely confined to patients with left bundle branch block, ${ }^{53}$ and it may even be that benefit is restricted to those with a QRS $>150 \mathrm{~ms}^{57}$

Similarly, while small non-randomised studies have reported variable benefit of CRT for patients in atrial fibrillation (AF), there is almost no evidence to support the practice from randomised trials. ${ }^{58}$ The few trials that included patients in AF showed no benefit with CRT. ${ }^{53}$ Although the European Society of cardiology guideline updates suggest that CRT might be considered in patients in $\mathrm{AF},{ }^{59}$ the class of recommendation was only IIa, level B or C.

What should all this mean in practice? CRT should certainly be considered for all patients with left ventricular systolic dysfunction and symptomatic heart failure who are in sinus rhythm and have left bundle branch block. CRT might be tried for those patients with intractable symptoms and AF (and left bundle branch block), but only if the ventricular rate is well controlled to maximise pacing. 
Better still, restoration of sinus rhythm in such patients may improve both quality of life and LV function ${ }^{60}$ while ensuring a more favourable response to CRT.

A more far-reaching question is whether patients with a standard bradycardia pacing indication would benefit from biventricular pacing. A small study using echocardiographic end points suggested that biventricular pacing was associated with less deterioration in left ventricular function, ${ }^{61}$ but whether widespread use of biventricular pacing is indicated will have to await the outcome of larger outcome studies.

\subsection{Exercise training}

The case for exercise training as a standard part of the management of patients with chronic heart failure has been building over several years. ${ }^{62}$ Training undoubtedly improves patients' symptoms and several of the predictors of an adverse prognosis. ${ }^{63}$ Mounting a properly powered survival study has proved difficult, not least because of the problems of blinding and the difficulty of cross-overs.

The HF-ACTION study managed to recruit 2331 patients randomised to usual care or an intensive training regimen (36 supervised 30 min sessions three times a week, followed by home exercise five times a week at moderate intensity for $40 \mathrm{~min}) \cdot{ }^{64}$ Although the primary end point of all-cause mortality and hospitalisation was no different between the two groups at a median follow-up of 30 months, there was a signal that training might be beneficial as after adjustment for baseline differences in predictors of outcome, training was associated with an $11 \%$ reduction in the primary end point. More importantly, perhaps, training was associated with a marked improvement in quality of life, which appeared early during the intervention and continued throughout the course of the study. ${ }^{65}$

It is still unclear whether the type of training stimulus is important: most evidence relates to aerobic training. A recent systematic review of trials of resistance training found that the quality of the studies has been poor and effects were inconclusive for quality-of-life outcomes. ${ }^{66}$

Incorporating exercise training into standard heart failure management is difficult. ${ }^{62}$ Compliance will always be a challenge-even in HF-ACTION, and after a year, patients' compliance with exercise was only about $80 \%$. Although home exercise is safe, ${ }^{64}$ initial supervision may be helpful for both patients and their carers and the resource implications are substantial. Whether a training programme is possible for many patients, who may be elderly, frail and have multiple comorbidities, is debatable. Nevertheless, patients can be reassured that exercise is safe and will improve their symptoms.

\subsection{Revascularisation}

The commonest cause of heart failure is underlying ischaemic heart disease. However, there is no good evidence that treatments directed at ischaemia with, for example, statins, ${ }^{67}$ are beneficial, despite the intuitive feeling that treating ischaemia should be effective. One of the more challenging questions has been whether revascularisation for patients with heart failure and no angina might be beneficial. Observational studies suggest that revascularisation might indeed improve prognosis, particularly in those with demonstrable viability on functional testing, ${ }^{68}$ but we now have two randomised trials that examine the problem directly.

In HEART, ${ }^{69}$ patients with heart failure and viable but dysfunctional myocardium were randomised to two strategies of care: conservative management or angiography with a view to revascularisation. There was no difference in survival between the two groups at 59 months. Although the trial recruited slowly and only 138 of the planned 800 patients were enrolled, there was no signal suggesting benefit.

$\mathrm{STICH}^{70}$ included 1212 patients with an ejection fraction $\leq 35 \%$ who were considered suitable for coronary artery bypass grafting (CABG). The patients were randomised to CABG or continued medical treatment. Over a median follow-up of 56 months, there was no difference in allcause mortality, the primary end point, between the treatment groups. The combined end point of all-cause mortality and cardiovascular hospitalisation was reduced in the CABG group, but the analysis excludes hospitalisation for the original operation, which is scarcely a negligible event: the 60 hospitalisations prevented by CABG required 555 hospitalisations for the CABG procedure itself. ${ }^{71}$ There were more deaths in the CABG group for more than 2 years after randomisation, emphasising that this is not a benign intervention.

Together, HEART and STICH show that there is, at most, a marginal benefit for revascularisation in patients with heart failure and underlying ischaemic heart disease. How the results relate to clinical practice is not clear: in STICH, the average age of patients was around 60 , resting heart rate was $>70$ (suggesting, perhaps, inadequate $\beta$ blockade) and fewer than $10 \%$ had 'chronic renal insufficiency' (creatinine is not reported in the paper). Despite the enormous effort expended to answer the question, it is still not clear whether revascularisation is helpful for patients with heart failure.

Acute heart failure

After many years of clinical trials in patients with chronic heart failure, there has been renewed interest in the problem of acute heart failure-in part, driven by the availability of new drugs as potential treatments.

One of the most widely used new treatments for acute heart failure has been nesiritide, licensed for use in the USA, largely as a results of trials showing some improvement in haemodynamics. ${ }^{72}$ It has always seemed a little strange from a European perspective that nesiritide has been so widely used and the European Medicines Agency did not allow its use in the EU. A 7000 patient trial comparing nesiritide with placebo in addition to standard treatment has now been completed. ${ }^{73}$ No statistically significant difference in symptoms scores was found between the two groups, or in rehospitalisation or death at 30 days.

Another agent for possible use in patents with acute heart failure is rolofylline, an adenosine antagonist. Rolofylline might help to prevent decline in renal function with diuretic treatment by interrupting glomerulotubular feedback. However, in a 2000 patient study, rolofylline had no effect on the primary end point (a composite 'treatment success' score), renal function or mortality. ${ }^{775}$

Taken together, the trials of rolofylline and nesiritide highlight the importance of using clinical trials appropriately to drive the evolution of treatment. Reliance on 
relatively small trials with inappropriate end points led to the nesiritide debâcle, whereas investigation of rolofylline followed an appropriate sequence with early small-scale studies informing the design of a properly powered endpoint study.

The correct diuretic dosing regimen for patients admitted with fluid retention has often been a controversial question and the DOSE trial ${ }^{76}$ was designed to help guide this aspect of acute heart failure management. Three hundred and eight patients with fluid retention due to heart failure were randomised to receive furosemide either as a bolus every $12 \mathrm{~h}$ or by continuous infusion: both were given as either low or high dose. There were two co-primary end points: patients' global symptom assessment over $72 \mathrm{~h}$ and change in creatinine level from baseline to $72 \mathrm{~h}$.

No significant difference was found between bolus and infusion regimens, but a small (and statistically non-significant) greater improvement in symptoms in the high-dose versus low-dose groups was seen. The high-dose groups had a substantially greater diuresis.

It can be difficult directly to compare practice in the USA with Europe. Typically, patients with acute heart failure are in hospital for around 5 days in the USA, but 11 days in Europe and any acute weight loss during admission (presumably reflecting fluid loss) is very much smaller, implying that patients are admitted in the USA with very much less fluid overload than in Europe. Whether there are differences between furosemide given by bolus or continuous infusion over a longer time scale cannot be addressed by DOSE, but the message that high doses of furosemide (defined here as 2.5 times the patient's usual oral dose) cause a greater diuresis is clear.

\section{REFERENCES}

1. Cleland JG, McDonagh T, Rigby AS, et al; National Heart Failure Audit Team for England and Wales. The national heart failure audit for England and Wales 2008-2009. Heart 2011;97:876-86.

2. National Heart Failure Audit.Report for 2009/10 http:// www.ic.nhs.uk/webfiles/Services/NCASP/audits\%20 and\%20reports/NHS National_Heart_Failure Audit 09 INTERACTIVE.pdf (accessed Jul 2011).

3. Wong $\mathrm{CY}_{2}$ Chaudhry SI, Desai $\mathrm{MM}_{2}$ et al. Trends in comorbidity, disability and polypharmacy in heart failure. Am J Med_2011;124:136_43.

4. Gurwitz JH, Goldberg RJ. Age-based exclusions from cardiovascular clinical trials: implications for elderly individuals (and for all of us): comment on "the persistent exclusion of older patients from ongoing clinical trials regarding heart failure". Arch Intern Med 2011;171:557-8.

5. National Institute for Clinical Excellence. Chronic Heart Failure. Clinical Guidleine 108. National Institute for Clinical Excellence, London, UK; 2010.

6. Al-Mohammad $\mathrm{A}_{2}$ Mant J. The diagnosis and management of chronic heart failure: review following the publication of the NICE guidelines. Heart 2011;97:411-16.

7. Joynt $\mathrm{KE}$, Orav EJ, Jha AK. The association between hospital volume and processes, outcomes and costs of care for congestive heart failure. Ann Intern Med 2011;154:94-102.

8. Macgowan GA, Parry G, Schueler $\mathrm{S}_{2}$ et al. The decline in heart transplantation in the UK. BMJ_2011;342:d2483.

9. Banner NR, Bonser RS, Clark AL, et al. Guidelines for referral and assessment of adults for heart transplantation..Heart. Heart 2011;97:1520-7.

10. Riezebos RK, Ronner E, Ter Bals E, et al; OPTIMA trial. Immediate versus deferred coronary angioplasty in nonST-segment elevation acute coronary syndromes. Heart 2009;95:807-12.

11. Inglis $\mathrm{SC}$,Clark RA, McAlister FA, et al__Structured telephone support or telemonitoring programmes for patients with chronic heart failure. Cochrane Database Syst Rev 2010;(8):CD007228.

12. Chaudhry SI, Mattera JA, Curtis JP, et al. Telemonitoring in patients with heart failure. N Engl J Med 2010;363:2301-9.

13. Koehler $\mathrm{F}_{2}$ Winkler $\mathrm{S}_{2}$ Schieber $\mathrm{M}_{2}$ et al; Telemedical Interventional Monitoring in Heart Failure Investigators. Impact of remote telemedical management on mortality and hospitalizations in ambulatory patients with chronic heart failure: the telemedical interventional monitoring in heart failure study. Circulation 2011;123:1873-80.

14. Bourge $\mathrm{RC}_{2}$ Abraham $\mathrm{WT}_{2}$ Adamson $\mathrm{PB}_{2}$ et al; COMPASSHF Study Group. Randomized controlled trial of an implantable continuous hemodynamic monitor in patients with advanced heart failure: the COMPASS-HF study.J Am Coll Cardiol 2008;51:1073-9.

15. Hoppe UC, Vanderheyden M, Sievert H, et al. Chronic monitoring of pulmonary artery pressure in patients with severe heart failure: multicentre experience of the monitoring Pulmonary Artery Pressure by Implantable device Responding to Ultrasonic Signal (PAPIRUS) II study.Heart 2009;95:1091_7.

16. Abraham WT, Adamson PB, Bourge RC, et al; CHAMPION Trial Study Group. Wireless pulmonary artery haemodynamic monitoring in chronic heart failure: a randomised controlled trial. Lancet 2011;377:658-66.

17. Ritzema J, Troughton $\mathrm{R}_{2}$ Melton $\mathrm{I}_{2}$ et al; Hemodynamically Guided Home Self-Therapy in Severe Heart Failure Patients (HOMEOSTASIS) Study Group. Physician-directed patient self-management of left atrial pressure in advanced chronic heart failure.Circulation_2010;121:1086-95.

18. Felker GM, Hasselblad V, Hernandez AF, et al. Biomarkerguided therapy in chronic heart failure: a meta-analysis of randomized controlled trials. Am Heart J2009;158:422_30.

19. Lainchbury JG, Troughton RW, Strangman KM, et al. $\mathrm{N}$-terminal pro-B-type natriuretic peptide-guided treatment for chronic heart failure: results from the BATTLESCARRED (NT-proBNP-Assisted Treatment To Lessen Serial Cardiac Readmissions and Death) trial. J Am Coll Cardiol 2009;55:53-60.

20. Owan TE, Hodge DO, Herges RM, et al. Trends in prevalence and outcome of heart failure with preserved ejection fraction._N Engl J Med 2006;355:251_9.

21. Bhatia RS, Tu JV, Lee DS, et al. Outcome of heart failure with preserved ejection fraction in a population-based study. $\mathrm{N}$ Engl J Med_2006;355:260_9.

22. Burkhoff D, Maurer MS, Packer M. Heart failure with a normal ejection fraction: is it really a disorder of diastolic function?_Circulation 2003;107:656-8.

23. Brutsaert DL, De Keulenaer GW. Diastolic heart failure: a myth.Curr Opin Cardiol_2006;21:240_8. 
24. Borlaug $\mathrm{BA}_{2}$ Jaber WA, Ommen $\mathrm{SR}_{2}$ et al. Diastolic relaxation and compliance reserve during dynamic exercise in heart failure with preserved ejection fraction. Heart 2011;97:964_9.

25. Holland DJ, Prasad SB, Marwick TH. Contribution of exercise echocardiography to the diagnosis of heart failure with preserved ejection fraction (HFpEF). Heart 2010;96:1024_8.

26. Tan $\mathrm{YT}_{2}$ Wenzelburger $\mathrm{F}_{2}$ Lee $\mathrm{E}$, et al. The pathophysiology of heart failure with normal ejection fraction: exercise echocardiography reveals complex abnormalities of both systolic and diastolic ventricular function involving torsion, untwist and longitudinal motion. J Am Coll Cardiol 2009;54:36-46.

27. Tan $\mathrm{YT}_{2}$ Wenzelburger $\mathrm{F}_{2}$ Lee $\mathrm{E}$, et al. Reduced left atrial function on exercise in patients with heart failure and normal ejection fraction. Heart 2010;96:1017-23.

28. Zile $\mathrm{MR}$, Gaasch $\mathrm{WH}_{2}$ Anand IS, et al; I-Preserve Investigators. Mode of death in patients with heart failure and a preserved ejection fraction: results from the Irbesartan in Heart Failure With Preserved Ejection Fraction Study (IPreserve) trial.Circulation_2010;121:1393-405.

29. Packer M, Poole-Wilson PA, Armstrong PW, et al. Comparative effects of low and high doses of the angiotensinconverting enzyme inhibitor, lisinopril, on morbidity and mortality in chronic heart failure. ATLAS Study Group. Circulation 1999;100:2312-8.

30. Konstam $\mathrm{MA}_{2}$ Neaton $\mathrm{JD}_{2}$ Dickstein $\mathrm{K}_{2}$ et $\mathrm{al}_{2}$ HEAAL Investigators. Effects of high-dose versus low-dose losartan on clinical outcomes in patients with heart failure (HEAAL study): a randomised, double-blind trial. Lancet 2009;374:1840_8.

31. Pitt B, Zannad F, Remme WJ, et al. The effect of spironolactone on morbidity and mortality in patients with severe heart failure. Randomized Aldactone Evaluation Study Investigators. N Engl J Med 1999;341:709_17.

32. Pitt $\mathrm{B}_{2}$ Remme $\mathrm{W}$, Zannad $\mathrm{F}_{2}$ et al;Eplerenone Post-Acute Myocardial Infarction Heart Failure Efficacy and Survival Study Investigators. Eplerenone, a selective aldosterone blocker, in patients with left ventricular dysfunction after myocardial infarction. N Engl J Med_2003;348:1309_21.

33. Zannad F, McMurray JJ, Krum H, et al; EMPHASIS-HF Study Group. Eplerenone in patients with systolic heart failure and mild symptoms. N Engl J Med_2011;364:11_21.

34. Juurlink DN, Mamdani MM, Lee DS, et al. Rates of hyperkalemia after publication of the Randomized Aldactone Evaluation Study. N Engl J Med_2004;351:543_51.

35. Pitt B, Anker SD, Bushinsky DA, et al; PEARL-HF Investigators. Evaluation of the efficacy and safety of RLY5016, a polymeric potassium binder, in a double-blind, placebocontrolled study in patients with chronic heart failure (the PEARL-HF) trial.Eur Heart J_2011;32:820_8.

36. Levine HJ. Rest heart rate and life expectancy. J Am Coll Cardiol 1997;30:1104-6.

37. Kjekshus JK. Importance of heart rate in determining betablocker efficacy in acute and long-term acute myocardial infarction intervention trials. Am J Cardiol 1986;57:43F-49F.

38. Swedberg $\mathrm{K}$, Komajda $\mathrm{M}_{2}$ Böhm $\mathrm{M}_{2}$ et al; SHIFT Investigators. Ivabradine and outcomes in chronic heart failure (SHIFT): a randomised placebo-controlled study. Lancet 2010;376:875-85.

39. Böhm M, Swedberg $K_{2}$ Komajda $M$, et al; SHIFT Investigators. Heart rate as a risk factor in chronic heart failure (SHIFT): the association between heart rate and out- comes in a randomised placebo-controlled trial. Lancet 2010;376:886-94.

40. Cullington $\mathrm{D}_{2}$ Goode $\mathrm{KM}$, Cleland JGF, et al. How many patients with chronic heart failure might be suitable for ivabradine? Heart In press.

41. Witte KK, Desilva $\mathrm{R}_{2}$ Chattopadhyay $\mathrm{S}_{2}$ et al_.Are hematinic deficiencies the cause of anemia in chronic heart failure? Am Heart J_2004;147:924-30.

42. Okonko DO, Grzeslo A, Witkowski T, et al. Effect of intravenous iron sucrose on exercise tolerance in anemic and nonanemic patients with symptomatic chronic heart failure and iron deficiency FERRIC-HF: a randomized, controlled, observer-blinded trial. J Am Coll Cardiol_2008;51:103-12.

43. Anker SD, Comin Colet J, Filippatos G, et al; FAIR-HF Trial Investigators. Ferric carboxymaltose in patients with heart failure and iron deficiency. N Engl J Med 2009;361:2436_48.

44. van der Meer P, Groenveld HF, Januzzi JL Jr, et al. Erythropoietin treatment in patients with chronic heart failure: a meta-analysis._Heart_2009;95:1309_14.

45. Beadle RM, Frenneaux M. Modification of myocardial substrate utilisation: a new therapeutic paradigm in cardiovascular disease. Heart 2010;96:824-30.

46. Lee L, Campbell R, Scheuermann-Freestone M, et al. Metabolic modulation with perhexiline in chronic heart failure: a randomized, controlled trial of short-term use of a novel treatment. Circulation 2005;112:3280-8.

47. G Fragasso, A Salerno, G Lattuada, et al_Effect of partial inhibition of fatty acid oxidation by trimetazidine on whole body energy metabolism in patients with chronic heart failure. Heart. Published Online First: 23 June 2011. doi:10.1136/ hrt.2011.226332.

48. Gao D, Ning N, Niu X, et al. Trimetazidine: a meta-analysis of randomised controlled trials in heart failure._Heart 2011;97:278_86.

49. Cleland JG, Daubert JC, Erdmann E, et al; Cardiac Resynchronization-Heart Failure (CARE-HF) Study Investigators, The effect of cardiac resynchronization on morbidity and mortality in heart failure. N Engl J Med 2005;352:1539_49.

50. Cleland JG, Calvert MJ, Verboven $Y_{2}$ et al. Effects of cardiac resynchronization therapy on long-term quality of life: an analysis from the CArdiac Resynchronisation-Heart Failure (CARE-HF) study.Am Heart J_2009;157:457_66.

51. Cleland JG, Freemantle N, Daubert JC, et al_LLong-term effect of cardiac resynchronisation in patients reporting mild symptoms of heart failure: a report from the CARE-HF study. Heart 2008;94:278_83.

52. Moss AJ, Hall WJ, Cannom DS, et al; MADIT-CRT Trial Investigators.Cardiac-resynchronization therapy for the prevention of heart-failure events. $\mathrm{N}$ Engl J Med 2009;361:1329_38.

53. Tang AS, Wells GA, Talajic $\mathrm{M}_{2}$ et al; Resynchronization-Defibrillation for Ambulatory Heart Failure Trial Investigators. Cardiac-resynchronization therapy for mild-to-moderate heart failure. N Engl J Med_2010;363:2385-95.

54. Chung ES, Leon AR2 Tavazzi L, et al. Results of the predictors of response to CRT (PROSPECT) trial. Circulation 2008;117:2608_16.

55. van Bommel RJ, Gorcsan J_3rd, Chung ES, et al_Effects of cardiac resynchronisation therapy in patients with heart failure having a narrow QRS Complex enrolled in PROSPECT. 
Heart_2010;96:1107-13.

56. Foley PW, Patel K, Irwin N, et al. Cardiac resynchronisation therapy in patients with heart failure and a normal QRS duration: the RESPOND study.Heart 2011;97:1041-7.

57. I Sipahi, TP Carrigan, DY Rowland, et al. Impact of QRS duration on clinical event reduction with cardiac resynchronization therapy. Meta-analysis of randomized controlled trials. Arch Intern Med. Published Online First: 20 June 2011. doi:10.1001/archinternmed.2011.247.

58. Lavalle $\mathrm{C}_{2}$ Ricci RP, Santini M.Atrial tachyarrhythmias and cardiac resynchronisation therapy: clinical and therapeutic implications. Heart_2010;96:1174_8.

59. Dickstein K, Vardas PE, Auricchio A, et al. 2010 Focused Update of ESC Guidelines on device therapy in heart failure: an update of the 2008 ESC Guidelines for the diagnosis and treatment of acute and chronic heart failure and the 2007 ESC guidelines for cardiac and resynchronization therapy. Developed with the special contribution of the Heart Failure Association and the European Heart Rhythm Association. Eur Heart J_2010;31:2677_87.

60. Shelton RJ, Clark AL, Goode $\mathrm{K}_{2}$ et al. A randomised, controlled study of rate versus rhythm control in patients with chronic atrial fibrillation and heart failure: (CAFE-II Study). Heart_2009;95:924-30,

61. Yu CM, Chan JY, Zhang Q, et al._Biventricular pacing in patients with bradycardia and normal ejection fraction. $\mathrm{N}$ Engl J Med_2009;361:2123_34.

62. Conraads VM, Beckers PJ.Exercise training in heart failure: practical guidance. Heart 2010;96:2025-31

63. Rees K, Taylor RS, Singh S, et al. Exercise based rehabilitation for heart failure. Cochrane Database Syst Rev 2004;(3):CD003331.

64. O'Connor $\mathrm{CM}$, Whellan DJ, Lee $\mathrm{KL}$, et al; HF-ACTION Investigators. Efficacy and safety of exercise training in patients with chronic heart failure: HF-ACTION randomized controlled trial.JAMA_2009;301:1439-50.

65. Flynn KE, Piña IL, Whellan DJ, et al; HF-ACTION Investigators. Effects of exercise training on health status in patients with chronic heart failure: HF-ACTION randomized controlled trial.JAMA_2009;301:1451_9.

66. Spruit MA, Eterman RM, Hellwig VA, et al. Effects of moderate-to-high intensity resistance training in patients with chronic heart failure. Heart 2009;95:1399_408.

67. Kjekshus J, Apetrei E, Barrios V, et al; CORONA Group.
Rosuvastatin in older patients with systolic heart failure. $\mathrm{N}$ Engl J Med 2007;357:2248-61.

68. Rizzello V, Poldermans D, Biagini E, et al._Prognosis of patients with ischaemic cardiomyopathy after coronary revascularisation: relation to viability and improvement in left ventricular ejection fraction. Heart 2009;95:1273-7.

69. Cleland JG, Calvert M, Freemantle N, et al. The Heart Failure Revascularisation Trial (HEART). Eur J Heart Fail 2011;13:227_33.

70. Velazquez EJ, Lee $\mathrm{KL}_{2}$ Deja MA, et al; for the STICH Investigators. Coronary artery bypass surgery in patients with left ventricular dysfunction. N Engl J Med_2011;364:1607_16.

71. Cleland JG, Freemantle N. Revascularization for patients with heart failure. Inconsistencies between theory and practice. Eur J Heart Fail_2011;13:694-7.

72. Publication Committee for the VMAC Investigators (Vasodilatation in the Management of Acute CHF). Intravenous nesiritide vs nitroglycerin for treatment of decompensated congestive heart failure: a randomized controlled trial. JAMA_2002;287:1531-40.

73. O'Connor $\mathrm{CM}_{2}$ Starling RC, Hernandez $\mathrm{AF}_{2}$,et al. Effect of nesiritide in patients with acute decompensated heart failure. N Engl J Med 2011;365:32-43.

74. Massie BM, O'Connor CM, Metra M, et al; PROTECT Investigators and Committees. Rolofylline, an adenosine A1-receptor antagonist, in acute heart failure. $\mathrm{N}$ Engl J Med 2010;363:1419-28.

75. Voors $\mathrm{AA}_{2}$ Dittrich $\mathrm{HC}_{2}$ Massie $\mathrm{BM}_{2}$,et al.Effects of the adenosine A1 receptor antagonist rolofylline on renal function in patients with acute heart failure and renal dysfunction: results from PROTECT (Placebo-Controlled Randomized Study of the Selective Adenosine A1 Receptor Antagonist Rolofylline for Patients Hospitalized with Acute Decompensated Heart Failure and Volume Overload to Assess Treatment Effect on Congestion and Renal Function). J Am Coll Cardiol_2011;57:1899_907.

76. Felker GM, Lee KL, Bull DA, et al; NHLBI Heart Failure Clinical Research Network. Diuretic strategies in patients with acute decompensated heart failure. N Engl J Med 2011;364:797_805.

Corresponding author: prof Andrew L. Clark, MD. Tel.: +44 (0) 1482 461775. E-mail: a.l.clark@hull.ac.uk 